\title{
GIORGIO AGAMBEN E A EMANCIPAÇÃO DA MULHER ${ }^{1}$
}

Yara Adario Frateschi (Unicamp) ${ }^{2}$

yfrateschi@gmail.com

Resumo: Este artigo investiga se e em que medida a teoria política de Giorgio Agamben oferece recursos para uma reflexão a respeito da questão da emancipação da mulher nas democracias capitalistas contemporâneas. Tratase de investigar se a teoria do Estado de Exceção nos municia para refletir e enfrentar a subjugação de gênero, que promove o bloqueio da participação da mulher na vida pública, a sua marginalização econômica e a sua dominação cultural. Pretendo sugerir que esta teoria talvez esteja internamente bloqueada para lidar com a questão de gênero, o que se deve fundamentalmente ao seu diagnóstico das democracias contemporâneas, resultante de um enfoque excessivo na máquina governamental e nas instituições dominadoras e da correspondente negligência da sociedade civil, das suas demandas específicas, das suas lutas e conquistas efetivas, ainda que parciais. Pretendo questionar ainda se, levado às suas últimas consequências, este diagnóstico não nos levaria a supor que as conquistas femininas, desde o final do século XIX, seriam ilusórias ou pouco significativas.

Palavras-chave: Giorgio Agamben; emancipação; gênero; Nancy Fraser; Seyla Benhabib.

A teoria do Estado de Exceção de Giorgio Agamben tem sido recebida com entusiasmo por intelectuais brasileiros de áreas diversas. Juristas, cientistas políticos, filósofos e psicanalistas têm se inspirado nela e frequentemente a aplicam ao atual estágio da democracia brasileira, inclusive para des-

\footnotetext{
${ }^{1}$ Recebido: 01-12-2015/ Aceito: 18-07-2016/ Publicado on-line: 28-08-2016.

${ }^{2}$ Yara Frateschi é Bolsista de Produtividade nível 2 do CNPq e Professora de Ética e Filosofia Política na Universidade Estadual de Campinas, Campinas, SP, Brasil.
} 
velar a sua contiguidade com a ditadura militar ${ }^{3}$. Na contramão dessa tendência, este texto analisa algumas das teses centrais da teoria do Estado de Exceção para mostrar as deficiências do diagnóstico que a embasa. Trata-se de um diagnóstico construído com excessiva atenção aos dispositivos de controle e à esfera pública oficial e que, por isso mesmo, não é atento para as demandas da sociedade, para a relevância dos movimentos sociais e para os potenciais emancipatórios inscritos no presente. Para empreender essa análise, me proponho a avaliar se e em que medida essa teoria nos ajuda a refletir sobre a questão da emancipação da mulher. Ainda que Agamben não tenha tratado desse tema, farei um exercício de pensá-lo a partir do seu arsenal teóri$\mathrm{co}^{4}$. Veremos que o modo pelo qual ele pensa as democracias capitalistas atuais dificulta a análise não apenas das conquistas das mulheres desde o fim do século XIX, mas também da complexidade dos obstáculos efetivos para a sua emancipação.

A primeira parte deste texto se concentra no diagnóstico que Agamben faz das democracias contemporâneas ocidentais principalmente nos livros Estado de Exceção, Homo Sacer e O Reino e a glória. Em um segundo momento, a partir de alguns elementos da Teoria Crítica de acordo com Seyla Benhabib, trata-se de explorar as deficiências desse diagnóstico, equivocado tanto em relação à "esfera pública

\footnotetext{
${ }^{3}$ No âmbito da filosofia é o caso, por exemplo, de Paulo Arantes. Cf. Arantes, Paulo. "1964 o ano que não terminou”. In Teles, Edson e Safatlle Wladimir (orgs). O que resta da ditadura. São Paulo: Boitempo Editorial, 2010.

${ }^{4}$ Eu poderia ter escolhido tratar da questão da discriminação racial (daquilo que se convencionou chamar de discriminação "racial", ainda que fosse mais adequado falar em "discriminação de cor") ao invés da questão de gênero, ambas candentes no Brasil contemporâneo, mas vou me restringir à primeira, anunciando de antemão que as conclusões a que chegarei aqui analisando a pertinência da teoria de Agamben para pensar a emancipação feminina valem também para a questão racial.
} 
oficial" quanto à "não oficial". Finalmente, num terceiro momento, recuperarei brevemente o modo como Nancy Fraser lida com a questão aqui proposta. Recorrei à análise que ela faz das injustiças que acometem as coletividades bivalentes para mostrar que a teoria de Agamben dificilmente oferece recursos para uma reflexão sobre a questão de gênero. A partir de Fraser e do modo como ela desvela a complexidade dos dilemas enfrentados pelas comunidades bivalentes, pretendo sugerir que a atenção excessiva nos dispositivos de controle - que tende a reduzir o Estado à sua faceta dominadora - e a identificação entre direito e violência (ou entre democracia e totalitarismo) levam Agamben a abandonar uma reflexão mais aprofundada sobre as possibilidades efetivas de combate à dominação e alienação na contemporaneidade. Afinal de contas, como veremos com Fraser, o enfrentamento do não reconhecimento passa por uma reflexão a respeito das políticas públicas mais adequadas para tanto, o que, no limite, está vetado para uma teoria que promove a tese da contiguidade entre democracia e totalitarismo e entende que a política contemporânea é integralmente biopolítica.

Em 1995, Agamben detecta um longo e duradouro eclipse da política que perdura "ainda hoje" e o atribui ao triunfo da biopolítica na modernidade (AGAMBEN 2007, p. 12). Duas das teses centrais de sua teoria são as seguintes: 1) Há um vínculo entre biopolítica e exceção soberana, eventos intimamente relacionados que se estabelecem com a política moderna e que revelam que a nossa política não conhece 
hoje outro valor além da vida; 2) Há uma "íntima solidariedade entre democracia e totalitarismo" (Ibidem). Para Agamben, a transformação moderna da política em espaço da vida nua é o que legitimou e tornou necessário o domínio total: "somente porque em nosso tempo a política se tornou integralmente biopolítica, ela pôde constituir-se em uma proporção antes desconhecida em política totalitária” (Idem, p. 126). Interessa destacar que, para ele, esse fenômeno se estende também às democracias, daí a tese da contiguidade entre democracia e totalitarismo:

[...] Antes de emergir impetuosamente à luz do nosso século [século XX], o rio da biopolítica que arrasta consigo a vida do homo sacer, corre de modo subterrâneo, mas contínuo. É como se, a partir de um certo ponto, todo evento político decisivo tivesse sempre uma dupla face: os espaços, as liberdades e os direitos que os indivíduos adquirem no seu conflito com os poderes centrais simultaneamente preparam, a cada vez, uma tácita porém crescente inscrição de suas vidas na ordem estatal, oferecendo assim uma nova e mais temível instância ao poder soberano do qual desejariam libertar-se. [...] E apenas porque a vida biológica torna-se por toda a parte o fato politicamente decisivo, é possível compreender a rapidez, de outra forma inexplicável, com a qual no nosso século [século XX] as democracias parlamentares puderam virar estados totalitários e os estados totalitários converter-se quase sem solução de continuidade em democracias parlamentares (AGAMBEN, p. 127-8, grifo meu) .

A essas teses soma-se outra, formulada anos depois em O Reino e a Glória, que afirma que a "função das aclamações e da glória, na forma moderna da opinião pública e do consenso, continua presente no centro dos dispositivos políticos do Ocidente" (AGAMBEN 2011, p.10). O livro de 2007 se ocupa do funcionamento da máquina governamental e conclui, após extensa pesquisa a respeito das doxologias e das aclamações litúrgicas, dos ministérios e dos hinos angélicos medievais, que há ainda hoje uma relação entre o 
poder e a glória que passa despercebida (principalmente para os teóricos do agir comunicativo), mas que revela "a verdadeira" estrutura e o funcionamento do poder, aliás com muito mais acerto, segundo ele, do que "muitas análises pseudo-filosóficas sobre a soberania popular, o Estado de Direito ou os procedimentos comunicativos que regem a formação da opinião pública e da vontade política" (Ibidem). Agamben redescobre a atualidade do diagnóstico de Debord, recuperando a identificação da democracia contemporânea com a sociedade do espetáculo. Nas suas palavras:

Em 1967, com um diagnóstico cuja precisão nos parece hoje mais que evidente, G. Debord constatava a transformação em escala planetária da política e da economia capitalista em um "imenso acumulo de espetáculos”, em que a mercadoria e o próprio capital assumem a forma midiática da imagem. Se juntarmos as análises de Debord com a tese schmittiana da opinião pública como forma moderna de aclamação, todo o problema do atual domínio espetacular da mídia sobre qualquer outro aspecto da vida social aparecerá em uma nova dimensão... O que está em questão é nada menos do que uma nova e inaudita concentração, multiplicação e disseminação da função da glória como centro do sistema político (AGAMBEN, p.278, grifo meu).

Para desfazer as ilusões causadas pelas teorias da democracia deliberativa baseadas na teoria do agir comunicativo, o autor, combinando Guy Debord com Carl Schmitt, defende que o que realmente importa para a compreensão do poder no atual estágio das democracias é o vínculo entre o poder e a glória. A suposta "democracia consensual" (que ele parece identificar equivocadamente com democracia deliberativa, como se toda forma de deliberação devesse terminar em consenso) é uma democracia gloriosa, na medida em que há um vínculo essencial entre consenso e aclama- 
ção: o consenso seria a forma moderna da aclamação (Idem, p. 281). Não vou analisar aqui detidamente a crítica de Agamben às teorias da democracia deliberativa e fazer o exercício necessário de desvelar as fragilidades do seu argumento que gira em torno da identificação entre deliberação e aclamação. Isso fica para outra ocasião. Basta, para o objetivo deste texto, notar que a construção do diagnóstico extremamente pessimista que Agamben faz foca na análise do funcionamento da máquina governamental, sempre dominadora, ao mesmo tempo em que prescinde da sociedade civil. Quando esta aparece, como é o caso no livro de 2007, é retratada como sujeito coletivo singular, um bloco unívoco formado por sujeitos indistintos e, mais ainda, totalmente passivos e controlados. Essa é a razão pela qual ele recusa solenemente a teoria do agir comunicativo: para ele, o povo não debate, mas aclama, a sociedade não é plural, mas singular (porque sua opinião é formada pela mídia), o diálogo público - até porque não acontece - não restringe ou pressiona o poder governamental, e a soberania popular é uma quimera que se desfaz quando atentamos para o vínculo entre o poder e a glória. Ocorre que ao tentar desfazer a "ficção” do govern by consent, Agamben desmerece o papel das instituições para a construção da igualdade democrática e, ao mesmo tempo, retira a sociedade de cena ignorando a sua capacidade de organização, mobilização e reivindicação. Sugiro estar aqui a raiz da inadequação do seu retrato das democracias contemporâneas bem como da incapacidade da sua teoria para detectar e enfrentar formas diversas de dominação, e, por conseguinte, a questão da emancipação da mulher.

No ensaio $O$ que é um dispositivo, essa prevalência da singularidade coletiva em detrimento da pluralidade e dos 
conflitos sociais se mostra com toda clareza quando ele recupera e atualiza os "dispositivos" de Foucault. Para ele, o que define:

Os dispositivos com os quais temos que lidar na atual fase do capitalismo é que estes não agem mais tanto pela produção de um sujeito quanto por meio de processos que podemos chamar de dessubjetivação [...] O que acontece agora é que processos de subjetivação e processos de dessubjetivação parecem tornar-se reciprocamente indiferentes e não dão lugar à recomposição de um novo sujeito, a não ser de forma larvar e, por assim dizer, espectral. (AGAMBEN 2009, p. 47)

$\mathrm{O}$ que isso significa? Significa que "as sociedades contemporâneas se apresentam como corpos inertes atravessados por gigantescos processos de dessubjetivação que não correspondem a nenhum processo de subjetivação real" (Idem, p.48, grifo meu). Daí o eclipse da política, que tenta se sustentar na "máscara hipócrita do bom cidadão democrático", mas que revela, na verdade, a formação do "corpo social mais dócil e frágil jamais constituído na história da humanidade (Idem, p.49). Na origem disso está uma certa concepção do indivíduo moderno para o qual estaria vetada qualquer possibilidade de comunicação e intersubjetividade, de organização, reivindicação e luta.

Que se tome, ainda, as teses segundo as quais a política contemporânea não conhece nenhum outro valor além da vida (a vida nua) e que o soberano decide a implicação originária do ser vivente na esfera do direito, o que legitima o domínio total. Com auxílio da teoria da democracia de Seyla Benhabib detectamos o vício que acompanha a redução integral da política à biopolítica. Em sociedades plurais e profundamente desiguais, observa Benhabib, "é muito difícil aceitar o outro enquanto profundamente diferente e ao mesmo tempo reconhecer sua igualdade e dignidade hu- 
mana fundamental" (BENHABIB, 2002, p.8). Portanto, é imprescindível, para a igualdade democrática, a criação de instituições que se contraponham à dominação. É possível, claro, que essas instituições não sejam imparciais e frequentemente não o são. Por isso, parte considerável da luta política é para que elas se tornem efetivamente democráticas e incorporem demandas legítimas. Mas a redução integral da política à biopolítica é tão cética a respeito das instituições e da luta pela sua democratização que, ao fim e ao cabo, conduz à inação: se tudo está perdido, por que lutar? O diagnóstico do eclipse da política leva Agamben a focar apenas nas perdas da modernidade, nunca nos seus ganhos e nas experiências efetivas de luta e emancipação. Além do mais, ele, que só pensa a política apenas partir da esfera pública oficial sempre dominadora e disciplinadora, desconsidera completamente aquilo que se passa ao largo dela, isto é, as lutas por reconhecimento e redistribuição. No entanto, um desvio de olhar que vai do Estado para a sociedade, do direito supostamente "congenitamente violento" para a mobilização social, coloca em cheque as teses acima destacadas a respeito do Estado de Exceção, dado que a "esfera pública oficial das instituições representativas, que incluem o legislativo, as burocracias públicas e executivas, o judiciário e os partidos políticos, não são os únicos lugares da contestação política e da formação da vontade e da opinião" (Idem, p.21, grifo meu). Em suma, não há como fazer um diagnóstico pertinente das democracias contemporâneas excluindo deliberadamente a presença dos movimentos sociais e das associações políticas, artísticas, religiosas, culturais e civis da esfera pública não oficial. Dito de outro modo, não há como fazer um diagnóstico pertinente das democracias atuais ignorando que reivindicações de grupos diversos se tornaram 
contestadoras na esfera pública das democracias capitalistas e estão implicadas em lutas por reconhecimento e redistribuição (Idem, p. 1). Mas do diagnóstico de Agamben estão excluídos esses atores e é evidente que eles precisam desaparecer para que a sociedade contemporânea possa ser retratada como um corpo inerte e como o "corpo social mais dócil e frágil jamais constituído na história da humanidade" (AGAMBEN 2007, p.49).

É importante notar que Agamben não esconde o seu modo de proceder, afinal ele diz claramente que o homem contemporâneo é aquele "que mantém fixo o olhar no seu tempo para nele perceber não as luzes, mas o escuro" (AGAMBEN 2007, 62). A sua atitude deliberada de "descrever a obscuridade" e "mergulhar nas trevas do presente" (Idem, p.63) revela, entretanto, mais um vício do seu diagnóstico, que parece vir antes de uma análise efetiva da sociedade das instituições e que se restringe a olhar para as patologias e para as forças impessoais que agem pelas costas dos agentes sociais. Essa atitude teórica obstrui a compreensão de como tais forças "geram certas experiências de sofrimento, humilhação, agressão e injustiça, que, por sua vez, podem levar à resistência, ao protesto e à luta organizada" (BENHABIB 1986, p.226). O resultado é que ele não detecta nenhuma mudança política significativa da Primeira Guerra Mundial até os dias de hoje, sugerindo, inclusive que nós estamos numa situação pior do que a da Roma republicana onde pelo menos a potestas estava separada da auctoritas $^{5}$. Ora, essa régua que Agamben passa na história é um indício de que talvez ele não considere relevantes as conquistas efetivas dos movimentos sociais e da sociedade

${ }^{5}$ Cf. Agamben, Giorgio. Estado de exceção. São Paulo: Boitempo Editorial, 2004, p. 131. 
em geral. A tese segundo a qual o evento fundador da modernidade é o ingresso da vida natural na esfera da polis e que a politização da vida nua como tal constitui o evento decisivo da modernidade desconsidera os ganhos e as conquistas promovidos, por exemplo, pelos movimentos de mulheres e as mudanças profundas que foram se dando, desde o século XIX, no que diz respeito ao confinamento da mulher ao lar, à sua aparição na esfera pública, à sua entrada no mercado de trabalho, à conquista do direito de voto, etc. $\mathrm{O}$ diagnóstico de que a modernidade juntamente com o capitalismo produziu apenas corpos "dóceis", ou seja, obedientes, impede Agamben de ver que muitas dessas conquistas são resultado de movimentos e lutas, que não teriam sido encampadas se o que estivesse em jogo na política fosse apenas o indivíduo enquanto simples corpo vivente.

Mais ainda, me parece que a lógica interna dessa teoria poderia levar à conclusão de que as lutas e conquistas femininas são uma ficção dado que o ingresso das mulheres no espaço público, a conquista da sua autonomia pessoal e financeira, a conquista do direito de voto e manifestação pública não podem significar outra coisa senão a reinserção de suas vidas na ordem estatal e a sua submissão ao controle do poder soberano aliado ao capital. Essa mesma lógica prejudica a percepção que são justamente essas conquistas que permitem ou podem vir a permitir que as mulheres se coloquem contra o "poder soberano" e defendam concepções de vida distintas daquelas sustentadas pela cultura androcêntrica, pela mídia, pela tradição e tenham liberdade para criticar determinadas concepções de bem contra os poderes instituídos, inclusive contra o Estado e a mídia. Se levasse a sério as lutas e as conquistas das mulheres, Agam- 
ben teria que colocar em questão a sua própria tese de que o corpo político do Ocidente é formado pelos corpos matáveis e dóceis dos súditos hobbesianos ${ }^{6}$.

II

Mas se Agamben não tem olhos para os ganhos democráticos, resta indagar se ele, que está à busca das trevas do presente, detecta com sagacidade as patologias contemporâneas. Parece, entretanto, que não são apenas os ganhos que ele deixa de ver, mas também as causas da injustiça e as dificuldades concretas para a emancipação das mais diversas formas de violência e dominação que vigem nas democracias atuais. Nessa sociedade homogênea e passiva que ele descreve, os indivíduos não têm nenhuma especificidade, razão pela qual Agamben está incapacitado de ver que a dominação e a injustiça ocorrem de modos diferentes, com instrumentos distintos, sobre pessoas e grupos específicos. Quando o Estado e as instituições são reduzidos a dispositivos de controle e a sociedade é descrita como um bloco homogêneo, passivo e indistintamente controlado, a dominação é vista apenas de um dos seus ângulos. Também por essa razão a sua teoria fica muito aquém de oferecer recursos para uma reflexão a respeito dos obstáculos efetivos à emancipação feminina, pois a injustiça contra a mulher não tem apenas uma face e uma causa que indiscriminadamente

\footnotetext{
${ }^{6}$ Cf. Agamben, Giorgio. Homo Sacer: o poder soberano e a vida nua. Belo Horizonte: Editora UFMG, 2007, p. 131. Tratei da atualidade da filosofia política de T. Hobbes segundo G. Agamben no texto "A atualidade da teoria hobbesiana da soberania de acordo com J. Rawls e G. Agamben". In: Villanova, Marcelo \& Lisboa, Wladimir (Orgs.). Hobbes: Natureza, história e política. Porto Alegre: EDIPUCRS/Córdoba: Brujas, 2011, p.189-206.
} 
afetaria sujeitos "dessubjetivados". A injustiça contra a mulher, como mostra Nancy Fraser, é econômica (material) e cultural (simbólica), sendo que ambas estão imbricadas reforçando-se mutuamente. Vejamos.

Fraser ressalta a imbricação da injustiça econômica e cultural, mostrando que quando normas androcêntricas e sexistas são institucionalizadas no Estado e na economia o resultado é a desvantagem econômica das mulheres e a restrição da sua participação na vida pública e na formação da cultura. Isso pereniza, por sua vez, normas androcêntricas e assim por diante: "o resultado é um círculo vicioso de subordinação cultural e econômica” (FRASER 2001, p.261). Apesar de considerar que injustiças econômicas e culturais estão imbricadas, Fraser se propõe a distingui-las analiticamente, não só porque de fato elas têm raízes e remédios distintos, mas também porque, ao detectar as suas especificidades, tornamo-nos capazes de lidar com um dilema importante das democracias contemporâneas .

A injustiça econômica, enraizada na estrutura políticoeconômica da sociedade, leva, por exemplo, à exploração do trabalho, à marginalização econômica e à privação de um padrão material adequado de vida. Em geral, as mulheres desempenham funções menosprezadas, são mal remuneradas e quando ocupam os mesmos postos de trabalho que os homens, os seus salários ainda são inferiores. A injustiça cultural - que é simbólica e não material - "está arraigada a padrões sociais de representação, interpretação e comunicação" (Idem, p.250) e se manifesta na dominação cultural, no não reconhecimento e no desrespeito. Interessa notar aqui que por não se contentar com uma análise simplória da injustiça recusando-se a reduzir a dominação a uma única faceta, Fraser se capacita para refletir também sobre os 
remédios (no plural) que possam combatê-la. Assim, o remédio para o primeiro tipo de injustiça não é exatamente o mesmo que o da segunda: "o remédio para a injustiça econômica é algum tipo de reestruturação político-econômica" (por exemplo, distribuição de renda, reorganização da divisão do trabalho, etc.), ao passo que o remédio para a injustiça cultural "é algum tipo de mudança cultural ou simbólica" (Idem, p.252). Mas admitir isso nos conduz a um dilema, que Fraser chama de dilema "redistribuiçãoreconhecimento": demandas redistributivas tendem a minar especificidades de grupos (ela dá o exemplo de demandas feministas pela abolição da divisão do trabalho por gênero), ao passo que demandas por reconhecimento tendem a reforçar a especificidade dos grupos. Portanto, se um mesmo grupo (que ela chama de "coletividades bivalentes", como é o caso das mulheres) demanda reparação nos dois sentidos, chegamos a um dilema, dado que as mulheres precisam ao mesmo tempo afirmar e negar suas especificidades .

Nancy Fraser não se contenta evidentemente em detectar o dilema entre redistribuição e reconhecimento. Trata-se de um momento da teoria - fortemente embasado na diversidade das reivindicações femininas - ao qual se segue a pergunta: como podemos sair desse dilema, próprio das coletividades bivalentes, entre afirmar e negar a própria identidade? Aqui me interessa mais a formulação da questão do que propriamente a resposta que Fraser dá para ela, pois ao nos darmos conta do dilema nos tornamos cientes de um sério déficit da teoria de Agamben. $O$ dilema se manifesta quando atentamos para as reivindicações concretas por reconhecimento e por redistribuição, assim como para os debates que ocorrem quando a sociedade se põe a refletir 
sobre quais remédios são mais adequados para desfazer injustiças contra coletividades bivalentes. Ou seja, o dilema se revela em experiências e práticas sociais concretas, que escapam a Agamben pelo fato mesmo de que essas experiências e práticas interessam pouco ou são imperceptíveis quando a sociedade é vista como inerte e passiva. Mais ainda, a pergunta pela possibilidade de resolver o dilema nos remete imediatamente para as políticas públicas que possam vir a combater as injustiças ${ }^{7}$, atitude que contrasta com o viés cético e passivo da teoria do Estado de Exceção que vê o Estado e as instituições em geral apenas pelo ângulo da biopolítica. Se Agamben não se interessa por políticas públicas que possam promover a igualdade democrática é porque, ao reduzir a política contemporânea à biopolítica, previamente decidiu que esta igualdade é inalcançável. Este é, no limite, o resultado de uma certa demonização do Estado. Por isso, novamente, interessam pouco as lutas concretas e, assim, a teoria se vê condenada por um diagnóstico que só capta dispositivo de controle (do lado das instituições) e passividade (do lado da sociedade), sem nenhum potencial para a emancipação e para o combate das injustiças.

Em contrapartida, ao se voltar para a resolução do dilema, Fraser se vê obrigada a analisar as virtudes e os vícios

\footnotetext{
${ }^{7}$ Isso é evidente, por exemplo, no caso do debate brasileiro recente sobre cotas para negros nas universidades públicas. A intensidade da polêmica em torno das cotas para negros revela não apenas que Agamben se equivoca quando retrata a sociedade atual como um corpo inerte, mas revela também que Fraser acerta em colocar o dilema entre afirmar e negar a especificidade de grupos sociais distintos quando se trata de pensar maneiras adequadas para combater a injustiça. A discussão recente sobre cotas para negros nas universidades públicas (e que também aparece no debate sobre cotas para mulheres em cargos ou listas partidárias) se dá numa disputa a respeito dos remédios mais adequados e eficazes para combater esse tipo de desigualdade, entre aqueles que defendem a ação afirmativa e aqueles que preferem remédios transformativos capazes de efetivamente combater a desigualdade e o racismo de maneira mais estrutural. A intensidade do debate e a natureza das questões que o norteiam revelam a complexidade do problema e as dificuldades de se enfrentar a dominação, questões simplesmente ausentes da obra de Agamben.
} 
dos remédios afirmativos e dos remédios transformativos e aqui se mostra a produtividade e a dimensão prática dessa teoria crítica orientada para a emancipação. Muito diferente de Agamben, que nada nos oferece para além de uma reiteração do diagnóstico da dominação total, Fraser nos oferece as razões pelas quais ela prefere certos remédios a outros $^{8}$. Ao invés de predefinir a sociedade como um corpo

\footnotetext{
${ }^{8}$ Interessa notar que o compromisso com o combate da injustiça institucionalizada, a partir de uma perspectiva universalista, leva Fraser a preferir remédios transformativos a remédios afirmativos. Remédios afirmativos para a injustiça são aqueles "voltados para a correção de resultados indesejáveis de arranjos sociais sem perturbar o arcabouço que os gera", ao passo que os transformativos "são orientados para a correção de resultados indesejáveis precisamente pela reestruturação do arcabouço genérico que os produz" (Fraser, Nancy. "Da redistribuição ao reconhecimento? Dilemas da justiça na era pós-socialista”. In Souza, Jessé (org). Democracia hoje. Novos desafios para a teoria política contemporânea. Brasília, UNB, 2001, p.265-6). Assim, remédios afirmativos redistributivos tentam superar a má-distribuição de recursos, mas deixam intacta a estrutura político-econômica subjacente. Algo análogo acontece com os remédios afirmativos de reconhecimento, pois estes tendem a promover as diferenciações entre os grupos, o que, segundo Fraser, dificulta reagrupamentos futuros. No caso do gênero, a "redistribuição afirmativa não afeta o nível profundo no qual a economia política é definida por gênero" e por isso tem que fazer continuamente realocações artificiais. $O$ reconhecimento afirmativo, por sua vez, ao afirmar a "diferença das mulheres", não apenas congela a "identidade" da mulher tal como ela é atualmente construída culturalmente, evitando a sua desconstrução, como também pode ter o efeito perverso de gerar ressentimento. De outro lado, os remédios transformativos redistributivos visam mudanças mais consistentes que evitam medidas artificiais constantes, ao mesmo tempo em que os remédios transformativos de reconhecimento visam "desmantelar o andocentrismo por meio da desestabilização das dicotomias de gênero" (idem, p. 276). Em 2003, no livro Redistribution and Recognition: A Political Philosophical Exchange, publicado em conjunto com Axel Honneth, Nancy Fraser modifica a sua estratégia inicial de distinguir remédios afirmativos e remédios transformativos incluindo a via media da "nonreformist reform", ideia que ela empresta de Andre Gorz. Essa correção no modo de conceber a diferenciação entre remédios afirmativos e transformativos se fez necessária diante da percepção de que a diferenciação original talvez pecasse por excesso de abstração e descontextualização (Conferir também "Global Justice and the Renewal of the Critical Theory Tradition”, in ROCKHILL, G. \& GOMEZ, M. Politics of Culture and the Spirit of Critique. New York, Columbia University Press, 2011, pp. 84-5). Para corrigir esse problema, ela passa a considerar que a diferença entre a estratégia afirmativa e a transformativa não é absoluta, mas contextual, pois "reformas que parecem ser afirmativas em abstrato, podem ter efeitos transformativos em alguns contextos se elas forem implementadas de maneira consistente e radical". Podemos pensá-las como "reformas não-reformistas" se, em certos contextos de implementação, elas forem capazes de colocar em movimento uma trajetória de mudanças na qual reformas mais radicais se tornem viáveis (Cf. Redistribution or Recognition? pp. 78-82). Isso não implica perder o horizonte das mudanças estruturais e tampouco abandonar pretensões universalistas. Significa, ao contrário, reconhecer que estratégias afirmativas podem ter consequências positivas para lutas futuras porque elas podem, dependendo do modo de implementação e do contexto, provocar mudanças maiores do que aquelas que elas visavam inicialmente.
} 
inerte, ela parte das reivindicações sociais e se compromete com elas, entrando no debate e justificando as suas posições; o que, por sua vez, a obriga a destacar a dimensão normativa da sua teoria bem como o seu compromisso com o universalismo e com o combate à injustiça institucionalizada $^{9}$. Como indiquei anteriormente, me interessa aqui menos a solução que Fraser dá para o problema e mais o modo como o formula e o enfrenta, atentando para as demandas sociais, para as causas da injustiça, para as possibilidades de revertê-la, o que exige a explicitação e justificação de um critério, baseado numa certa concepção e modelo de democracia, que a orienta no momento de enfrentar o problema da dominação. Quando se assume a tarefa de enfrentar o problema da dominação e refletir sobre as políticas públicas, torna-se imprescindível lançar mão de critérios e justificá-los, o que, por sua vez, só se faz premente quando se reconhece, do outro lado, algo mais do que sujeitos "dessubjetivados" e inertes. A tarefa da justificação de critérios é desnecessária, em contrapartida, quando o teórico se con-

\footnotetext{
${ }^{9}$ Não vou analisar detidamente a resposta de Fraser para essas questões e o modo pelo qual ela tenta encontrar uma solução para o dilema destacado acima. Vale mencionar, contudo, que ela sustenta uma concepção bi-dimensional de justiça, que trata a distribuição e o reconhecimento como perspectivas distintas da justiça, sem reduzir uma a outra. A noção de paridade de participação funciona como padrão normativo para a sua concepção de justiça, trata-se de uma norma universal e serve para avaliar se as condições para a deliberação estão dadas ou não. Duas observações a esse respeito: 1) a paridade de participação é universalista em dois sentidos: porque ela inclui todos os parceiros (adultos) na interação e porque pressupõe o valor moral igual dos seres humanos; 2) a paridade de participação "deve ser aplicada dialogicamente e discursivamente no decorrer de processos democráticos de debate público" (Cf. Fraser, Nancy \& Honneth, Axel. Redistribution or recognition? A political-philosophical Exchange. London: Verso, 2003, p.43-5). De acordo com essa norma, a justiça requer arranjos sociais que permitam que todos os membros da sociedade interajam com os outros como pares. Isso significa que para que a paridade de participação seja possível duas condições devem ser satisfeitas: primeiro, a distribuição dos recursos materiais deve ser de tal modo que assegure a independência e a voz dos participantes. Ela chama essa condição de "condição objetiva da paridade de participação". A segunda condição requer que padrões de valor cultural institucionalizados expressem igual respeito por todos os participantes e assegure iguais oportunidades para a aquisição da estima social. Essa condição ela chama de "condição intersubjetiva da paridade de participação" (idem, p. 36).
} 
tenta em revelar "as trevas do presente" para uma audiência que ele predefiniu - em seu gabinete - como "os corpos matáveis dos súditos hobbesianos" e que, portanto, não debate, mas apenas "aclama".

Como mencionei anteriormente, a tese da contiguidade entre democracia e totalitarismo e o ceticismo em relação à possibilidade da formação intersubjetiva da vontade e da opinião levam Agamben a rejeitar as teorias da democracia deliberativa: "a democracia contemporânea é uma democracia inteiramente fundada na glória, ou seja, na eficácia da aclamação, multiplicada e disseminada pela mídia além do que se possa imaginar" (AGAMBEN 2011, p.278). Mas a recusa da existência do diálogo público, decorrente da identificação entre deliberação e aclamação, tem como efeito a inação, ou seja, a conservação da dominação. Se entendemos, por outro lado, que democracia implica a participação dos concernidos nos processos decisórios, a ampliação da democracia requer a inclusão do maior número de cidadãos e cidadãs nesses processos e nas instituições nas quais se dão a deliberação e a formulação de políticas públicas. Não sabemos qual é o modelo de democracia de Agamben, mas sabemos que ele desdenha dos "procedimentos comunicativos que regem a formação da opinião e da vontade política” (Idem, p. 10). Logo, o seu foco não está evidentemente na deliberação pública (uma quimera) e tampouco na avaliação dos obstáculos reais à ampliação da participação de públicos específicos. Isso vem junto com a negligência do fato de que movimentos sociais têm procurado, não é de hoje, desfazer os bloqueios à participação de grupos específicos e historicamente alijados dos processos decisórios. Não é à toa, portanto, que ele simplesmente ignora um dos mais significativos movimentos 
sociais da sua própria época, o movimento feminino. Se a sua teoria não lida com as condições de possibilidade da ampliação da participação em geral, por que interessaria uma reflexão sobre as condições de possibilidade da ampliação da participação das mulheres nos processos decisórios? No que diz respeito à exclusão das mulheres, não basta dizer que a política moderna substitui a vida qualificada do cidadão pela vida nua (o que parece valer, indiscriminadamente, para homens e mulheres), é preciso esclarecer o caráter e as causas da subordinação da mulher e da sua exclusão dos processos decisórios. Ocorre que ao eleger a vida nua como único valor na modernidade, Agamben iguala homens e mulheres sob a categoria "corpos dóceis" e faz desaparecer a questão de gênero. Os corpos dóceis e a vida nua são neutros quanto ao gênero.

\section{III}

Diferentemente da teoria do Estado de Exceção, a Teoria Crítica se volta para as necessidades e demandas expressadas pelos atores sociais no presente, de modo que o diagnóstico das democracias atuais, que está sempre em reformulação, se constrói a partir de uma análise dessas demandas. Como diz Benhabib:

[...] a teoria crítica social não está exclusivamente interessada nas forças impessoais que agem pelas costas dos agentes sociais, mas em mostrar como tais forças geram certas experiências de sofrimento, humilhação, agressão e injustiça, que, por sua vez, podem levar à resistência, ao protesto e à luta organizada. (BENHABIB 1986, p.226)

Em contraste, Agamben parece interessado apenas nas "forças impessoais" das quais fala Benhabib, razão pela qual 
ele se concentra, sobretudo, nos dispositivos de controle (do Estado e da mídia) que, segundo ele, levam à "dessubjetivação" dos sujeitos contemporâneos. Que essas forças ocorrem pelas costas dos sujeitos, não há dúvida, dado que as sociedades contemporâneas são, para ele, corpos inertes "atravessados por gigantescos processos de dessubjetivação". Mas se os sujeitos são "dessubjetivados", somem todas as suas especificidades, são todos - brancos e negros, heterossexuais, homossexuais, lésbicas, transexuais, homens e mulheres de todas as classes - igualmente controlados pelos mesmos dispositivos. Desaparecem as especificidades culturais bem como as experiências concretas de desrespeito sofridas por indivíduos e grupos distintos. Tanto é assim que quando Agamben se refere aos "sujeitos" concretos é para dizer que estamos todos controlados pelas câmeras espalhadas nas ruas, pelos telefones celulares e que nos sentimos livres apenas quando zapeamos no controle remoto da televisão (AGAMBEN 2007, p. 47-8). Portanto, não faz sentido perguntar pelas suas experiências de sofrimento, humilhação e injustiça especificas. Por essa razão ainda, a teoria não parece oferecer recursos para uma reflexão a respeito das condições de possibilidade da reversão desse processo inelutável de "dessubjetivação", que Agamben detecta como a patologia da política contemporânea. Se desaparecem os "sujeitos", some junto com eles a possibilidade da emancipação .

O beco sem saída a que essa teoria nos conduz tem sua raiz nesse esfacelamento dos indivíduos e na visão da sociedade como uma singularidade coletiva obediente. Em conformidade com isso, Agamben afirma que o campo (o de concentração!), enquanto "puro, absoluto e insuperado espaço biopolítico (...) é o paradigma oculto do espaço políti- 
co da modernidade" (AGAMBEN 2007, p. 129). Como é que "corpos inertes" ou "corpos dóceis" poderiam resistir, protestar e se organizar em reação às suas experiências de sofrimento e humilhação? Que tipo de resistência é possível no "campo"? Vemos assim que o grande esforço "crítico" de Agamben, desde o Estado de exceção (2003) até O reino e a glória (2007), termina exatamente onde começou: afirmando e reafirmando, de um lado, os dispositivos da máquina governamental e o funcionamento do poder e, de outro, a vida nua, os sujeitos dessubjetivados, os corpos matáveis dos súditos hobbesianos .

Agamben retrata os cidadãos das democracias contemporâneas como dóceis e obedientes, mas fala em uma política "por inventar" (Idem, p.18). Ele defende que o direito é intrinsecamente violento, mas sonha com o dia em que "a humanidade poderá brincar com o direito, como as crianças brincam com os objetos fora de uso, não para devolvêlos ao seu uso canônico, mas para libertá-los [os brinquedos] definitivamente dele [do uso canônico]" (Agamben 2004, p.98). Do domínio total a uma política nova, da violência à brincadeira, do estado de direito ao estado sem direito: devemos nos perguntar como se fazem essas passagens e como se dá a emancipação? Agamben não tem como dar respostas a essas questões justamente porque desconsidera os agentes da resistência e da transformação social. Para levá-los em consideração seria necessário, parafraseando Marx, começar por analisar e esclarecer, sem dogmatismo e predefinição, as "lutas e desejos de sua época"10.

\footnotetext{
${ }^{10}$ Marx, K. Carta a Arnold Ruge, setembro de 1843. Cf. Fraser, Nancy. "O que é crítico na teoria crítica? O argumento de Habermas e o gênero". In Benhabib, Seyla \& Cornell, Drucilla (orgs). Feminismo como crítica da modernidade. Rio de Janeiro: Editora Rosa dos Tempos, 1987, p.38.
} 
Abstract: This paper investigates whether and to what extent Giorgio Agamben's political theory offers theoretical resources to reflect on the issue of the emancipation of women in contemporary capitalist democracies. My goal is to investigate whether the Estate of Exception theory helps us to think about gender subjugation, which causes the constraint of women's participation in public life, their economic marginalization and cultural domination. I intend to suggest that this theory is internally blocked to deal with the gender issue, which is mainly due to its diagnosis of contemporary democracies based on an excessive focus on government machinery and dominant institutions and the related negligence of civil society, its specific demands, its struggles and effective achievements. I also intend to question if this diagnosis would suggest that women's achievements, since the end of the nineteenth century, are illusory or not significant.

Keywords: Giorgio Agamben; emancipation; gender; Nancy Fraser; Seyla Benhabib.

\section{REFERÊNCIAS}

AGAMBEN, Giorgio. Homo Sacer: o poder soberano e a vida nua. Belo Horizonte: Editora UFMG, 2007.

- O reino e a glória. São Paulo: Boitempo Editorial, 2011.

- O que é o contemporâneo e outros ensaios. Chapecó: Argos, 2009.

. Estado de exceção. São Paulo: Boitempo Editorial, 2004.

ARANTES, Paulo. 1964 o ano que não terminou. In Teles, Edson e Safatlle Wladimir (orgs). O que resta da ditadura. São Paulo: Boitempo Editorial, 2010.

ARENDT, Hannah. "Algumas questões de filosofia moral”. In Responsabilidade e julgamento. São Paulo: Companhia das Letras, 2004.

. O que é política?. Rio de Janeiro: Bertrand Brasil, 
2007.

BENHABIB, Seyla. Claims of culture. Equality and diversity in the global era. Princeton: Princeton University Press, 2002.

. Critique, norm and utopia. A study of the foundations of critical theory. New York: Columbia University Press, 1986.

FRASER, Nancy. "Da redistribuição ao reconhecimento? Dilemas da justiça na era pós-socialista”. In Souza, Jessé (org). Democracia hoje. Novos desafios para a teoria política contemporânea. Brasília: UNB, 2001.

- "O que é crítico na teoria crítica? $\mathrm{O}$ argumento de Habermas e o gênero". In Benhabib, Seyla \& Cornell, Drucilla (orgs). Feminismo como crítica da modernidade. Rio de Janeiro: Editora Rosa dos Tempos, 1987.

FRASER, Nancy \& HONNETH, Axel. Redistribution or recognition? A political-philosophical Exchange. London: Verso, 2003.ROCKHILL, G. \& GOMEZ, M. Politics of Culture and the Spirit of Critique. New York: Columbia University Press, 2011. 